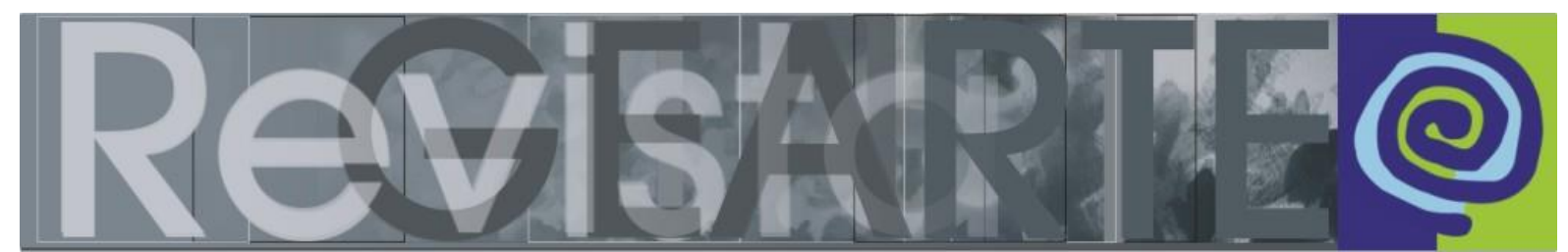

ISSN 2357-9854 | e-ISSN 2596-3198 (online)

\title{
Propuesta de colaboración con futuros docentes de educación infantil. Bocadillos temáticos, series, performances e instalaciones
}

\author{
Pilar Pérez Camarero \\ (Universidad Autónoma Madrid — UAM, Madrid/ España) \\ María Ángeles Alegre del Rey \\ (Universidad Autónoma Madrid — UAM, Madrid/ España)
}

\begin{abstract}
RESUMEN - Propuesta de colaboración con futuros docentes de educación infantil. Bocadillos temáticos, series, performances e instalaciones - El artículo presenta el análisis pedagógico de una experiencia de formación para futuros docentes de educación artística en educación infantil en la Universidad Autónoma de Madrid. Siga el camino y los fundamentos a través de los cuales se llevó a cabo el proyecto. Esta propuesta es un proceso innovador basado en el dinamismo y la autogestión, que invita a los participantes, tanto estudiantes como profesores. El trabajo se desarrolló a través de la observación y los indicadores se obtuvieron mediante la elaboración del diario de campo, generando así reflexión y se generan actividades de sensibilización y pensamiento pedagógico artístico.
\end{abstract}

PALABRAS CLAVE

Innovación. Educación artística. Performance. Diarios de campo. Conciencia.

\begin{abstract}
Collaborative proposal with future teachers of child education. Theme snacks, series, performances and installations - The article presents the pedagogical analysis of a training experience for future teachers of art education in child education at the Autonoma University of Madrid. It addresses the methodological path and the fundamentals through which the project was carried out. This proposal is an innovative process based on dynamism and self-management, involving participants, both students and teachers. The work was developed through observation and the indicators were obtained through the elaboration of the field diary. The observations and data from the field diary generated reflections and activities to raise awareness and artistic pedagogical thinking.

\section{KEYWORDS}

Innovation. Art education. Performance. Field diary. Awareness.

RESUMO - Proposta colaborativa com futuros professores da educação infantil. Lanches temáticos, séries, performances e instalações - $O$ artigo apresenta a análise pedagógica de uma experiência de formação para futuros professores de educação artística na educação infantil na Universidade Autônoma de Madrid. Aborda o percurso metodológico e os fundamentos através dos quais o projeto foi realizado. Esta proposta constitui um processo inovador com base no dinamismo e na autogestão, envolvendo os participantes, tantos os alunos como os professores. $O$ trabalho se desenvolveu através de observação e os indicadores foram obtidos através da elaboração do diário de campo, gerando assim reflexões e atividades de sensibilização e pensamento pedagógico artístico.

\section{PALAVRAS-CHAVE}

Inovação. Ensino da Arte. Performance. Diários de campo. Consciência. 


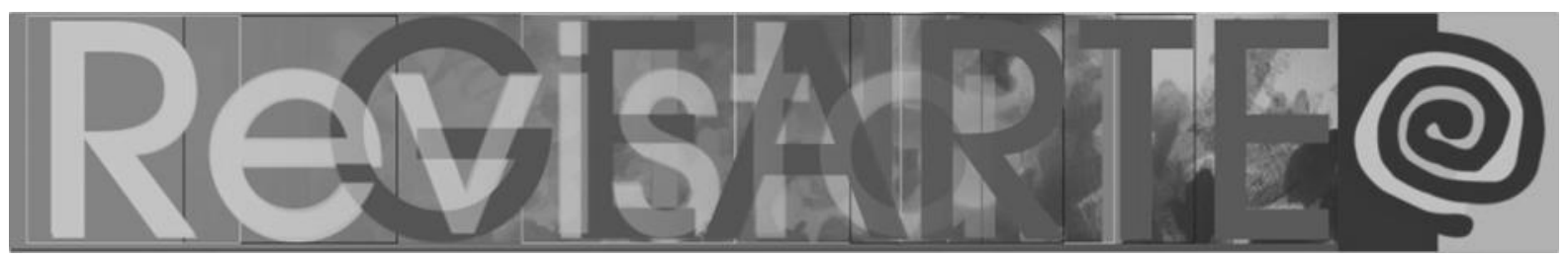

"Toda capacidad es esencia" (GADAMER).

La propuesta de trabajo interactiva que a continuación presentamos se llevó a cabo durante el curso académico 2018-2019. Derivó de un proyecto de innovación que implicó un trabajo de investigación/acción transformadora de lo que acontece en el aula, teniendo su origen en otros proyectos anteriores desarrollados desde el curso académico 2014-2015.

El proyecto se implementó en la asignatura "Fundamentos de la Educación Artística, Plástica y Visual” para la Educación Infantil. Se trata de una asignatura troncal, obligatoria, con una docencia de nueve créditos presenciales y cinco horas por semana de las cuales los estudiantes tienen que permanecer tres horas y media en el aula. El horario es continuado.

A lo largo de estos años hemos ido desarrollando una forma de intervención en las clases de educación artística, en las que a partir del formato oficial de aula de una hora y media de práctica + hora y media de práctica (dividiendo el grupo total de estudiantes en dos secciones) y dos horas de teoría dirigida a todo el grupo, articulábamos una dinámica flexible de todo este contenido llegando a constituir un sistema a través del cual el estudiante se autoregulaba, de tal forma que necesitaba autogestionar su obligatoria permanencia de tres horas y media en la clase a partir de las cinco horas de trabajo continuo de taller.

En el proyecto de innovación que llevamos a cabo entendíamos que la incorporación a la práctica docente de aspectos referidos a la inclusión, igualdad, y sostenibilidad pasan ineludiblemente por procurar la autogestión de los estudiantes de tal manera que la misma se nutra de una permanente interiorización e integridad de la toma de decisiones. Una toma de decisiones que dialoga con los dinamismos del hecho educativo comprendiendo que el vínculo que se establece en las tres vías esenciales de la comunicación (intrapersonal, interpersonal y trascendental) confluye en la convergencia de lo individual y lo social. Se trata de base y en un principio desde un enfoque pedagógico "radical inclusivo" (siguiendo 


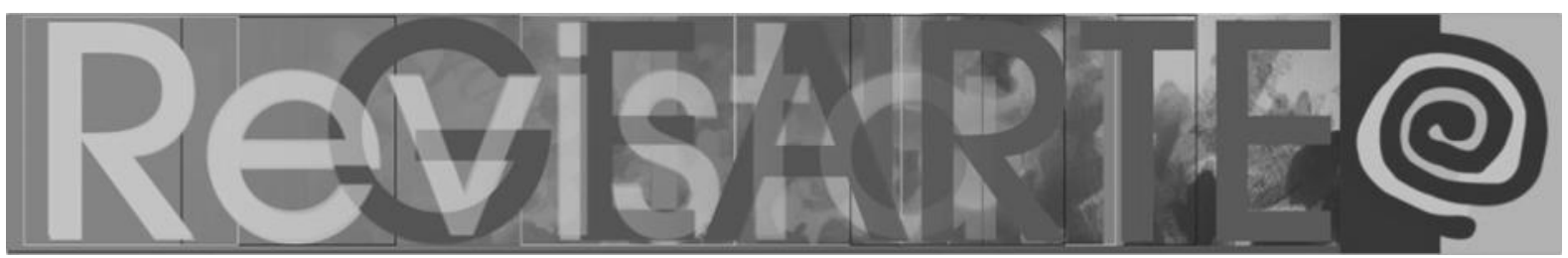

a Agustín de la Herrán) de poner foco en el vínculo educativo, pues se entiende cargado de potencial creador por contener el germen más consustancial al contexto donde se desarrolla la acción docente. Nuestra materia es eminentemente teórico/práctica y una cosa va enlazada con la otra.

La flexibilidad en el tiempo, dentro de la responsabilidad del obligado estándar, ha producido en estos años una interesante sinergia en que los estudiantes alentados a través de un enfoque pedagógico de talante reflexivo e interpretativo se han autogestionado y han sido partícipes de lo que ocurría en la clase, desde la propia decisión en una primera instancia de cómo solucionar los tiempos de permanencia.

Este enfoque ha permitido trabajar en pequeño grupo y en gran grupo con gran fluidez, desarrollando asambleas, acercando la realidad del aula de la Universidad a su futuro trabajo como docentes y cada año, los estudiantes han sido gestores y protagonistas de los procesos de enseñanza/aprendizaje en un tipo de dinámica en la que cada curso hemos contado con procesos diversos, donde se ha hecho presente la idiosincrasia de cada grupo y de las características particulares de sus miembros.

Como hitos en el recorrido que precede a la actividad propia que estamos señalando tenemos los siguientes:

En el primer año (2014-2015) se generó un trabajo en torno a identidades y concretamente a la construcción/deconstrucción de muñecas estereotipadas siguiendo a la artista de Tasmania Sonia Singh, que derivó en una exposición docente y un catálogo editado ${ }^{1}$ por el Departamento de Educación Artística. Fue un proyecto que se desarrolló en colaboración con la profesora Marta Lage,

1 PÉREZ, Pilar. (Org.). De muñeca estereotipada a gente 'normal'. Madrid: Universidad Autónoma de Madrid, 2016. Link del catálogo online (también se editó versión en papel): https://www.academia.edu/30516684/De_mu\%C3\%B1eca_estereotipada_a_gente_normal 


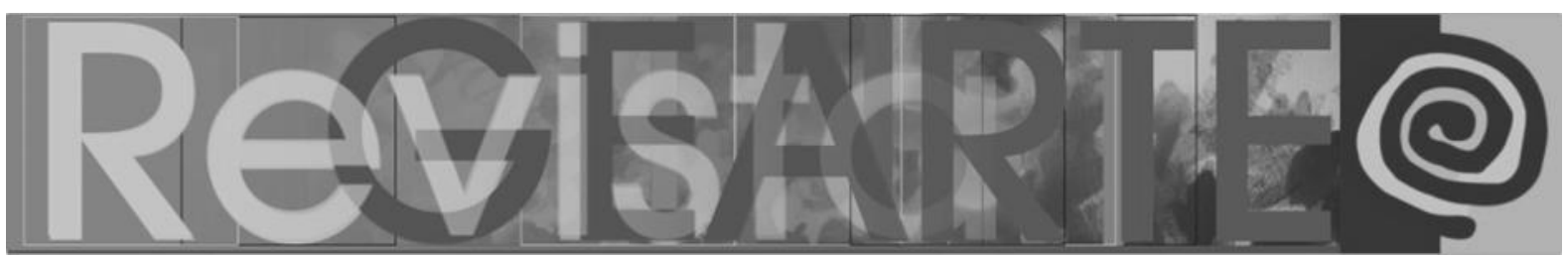

actualmente docente en la Universidad Complutense de Madrid. Como materiales de difusión de esta investigación/acción: "Transformando una muñeca: arquetipos y proyección simbólica a través de un taller de arte"2 y "Muñecas como yo: volver a pensar las muñecas"3.

En el año 2015-2016, se trabajó el cuento de Blancanieves elaborando un proceso de construcción colectiva que produjo una performance y la edición de un vídeo. En este año colaboramos con la profesora brasileña Daniella Zanellato de forma longitudinal en el aula, y con Mónica Sánchez. El material de divulgación textual fue: "O Ensino da Arte como espaço para a reflexão ética. Enfrentar o problema do mal através de uma experiência em sala de aula: Branca de Neve os predadores internos/externos da psique"4. Y el material de difusión audiovisual está disponible en YouTube 5 .

En los cursos 2016/17 y en el 2017/2018 se desarrolló la performance colaborativa "Yo visto a mi maestra" reflexión performática sobre los roles profesor/estudiante, siguiendo a Marina Abramovich, y su performance Ritmo 0. En el primer año se elaboró también material diverso en torno a los sueños y el imaginario y en el siguiente el proceso se concentró en la revisión del cuento Caperucita Roja, terminando con un vídeo colectivo a partir de diversos vídeo-clips

2 PÉREZ CAMARERO, Pilar. Transformando una muñeca: arquetipos y proyección simbólica a través de un taller de arte". Actas de El cuerpo como medida, Universidad Rey Juan Carlos. Editora MaJesús Abad Tejerina. ISBN- 978-84-608-1694-2 (pp 138-149p), 2016. Disponible en: https://eciencia.urjc.es/bitstream/handle/10115/14461/elcuerpocomomedida2.pdf?sequence=1 \&isAllowed=y. Acceso en: 10 diciembre 2019.

3 LAGE DE LA ROSA, Marta; PÉREZ CAMARERO, Pilar. Muñecas como yo: volver a pensar las muñecas. Padres y maestros. Revista de Investigación e Información Pedagógica, n. 375, p. 28-31, sept. 2018. Disponible en: https://fund-encuentro.org/index.php/padresymaestros/issue/view/654. Acceso en: 12 diciembre 2019.

4 PÉREZ CAMARERO, Pilar. O Ensino da Arte como espaço para a reflexão ética. Enfrentar o problema do mal através de uma experiência em sala de aula: Branca de Neve e os predadores internos/externos da psique. 492 Revista GEARTE, Porto Alegre, v. 5, n. 3, p. 492-515, set./dez. 2018. http://dx.doi.org/10.22456/2357-9854.88323

5 Material de difusión audiovisual disponible en YouTube: https://www.youtube.com/watch?v=0i2EjbkLtnQ, https://www.youtube.com/watch?v=su9zy_WYtxc\&t=176s 


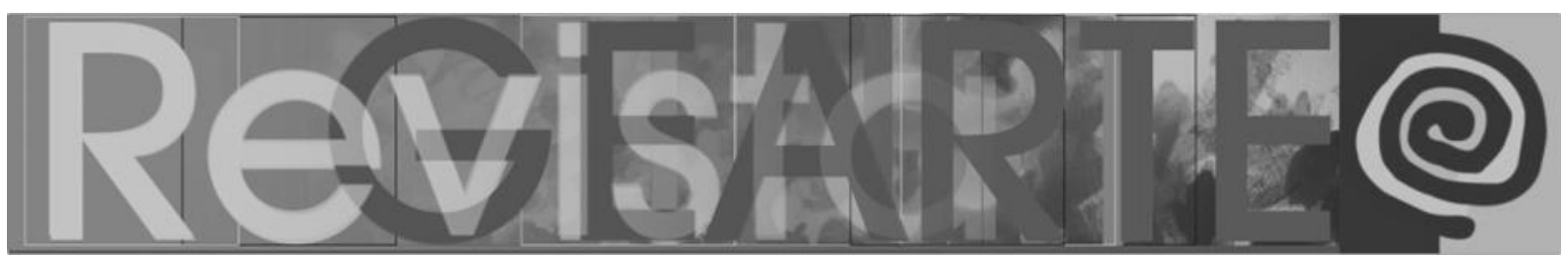

con marionetas. El proyecto "Yo visto a mi maestra" evolucionó del primer al segundo año, en que fue más interactivo por parte de los estudiantes, que quisieron continuar un material iniciado por sus compañeros con la profesora el año anterior. El material de divulgación visual del trabajo con Caperucita Roja ${ }^{6}$ en YouTube.

Finalmente en el año 2018-2019 se incorporó como co-docente, la Orientadora Escolar María Ángeles Alegre (coautora de este artículo) como Profesora Honoraria. Trabajamos desde el inicio la decodificación de la cultura visual de series y documentos contemporáneos que consume nuestro entorno. Realizamos un camino poniendo un punto de reflexión en torno a la realidad de las aulas y los niños gracias al trabajo de María Ángeles Alegre en la escuela pública. La clase se gestionó por los estudiantes de forma autónoma incorporando unos patrones que se discutieron y construyeron con ellos, que incluyeron visionados, análisis, performance, músicas temáticas, arte con comida (Figura 1), y dinámicas varias aplicadas al aula.

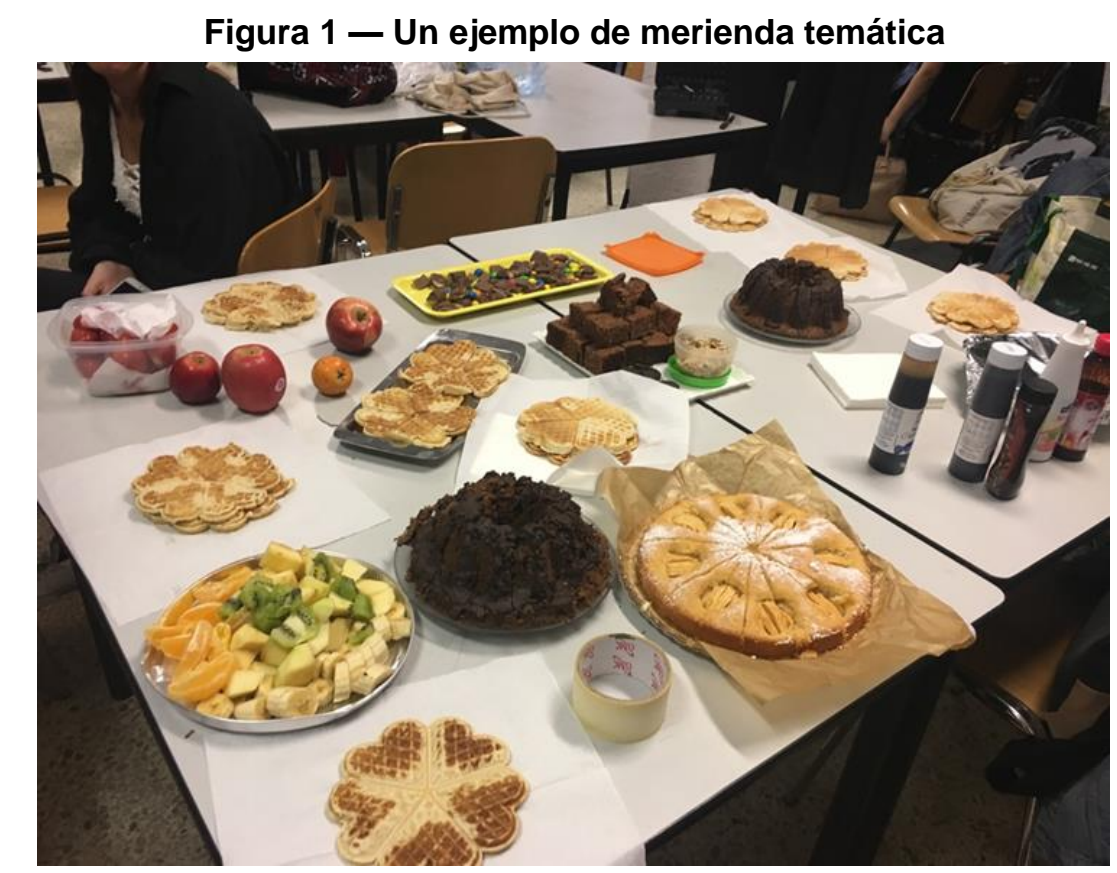

Fuente: Archivo de las autoras.

6 Material de divulgación visual del trabajo con Caperucita Roja: https://www.youtube.com/watch?v=MqglbAu4wn8 


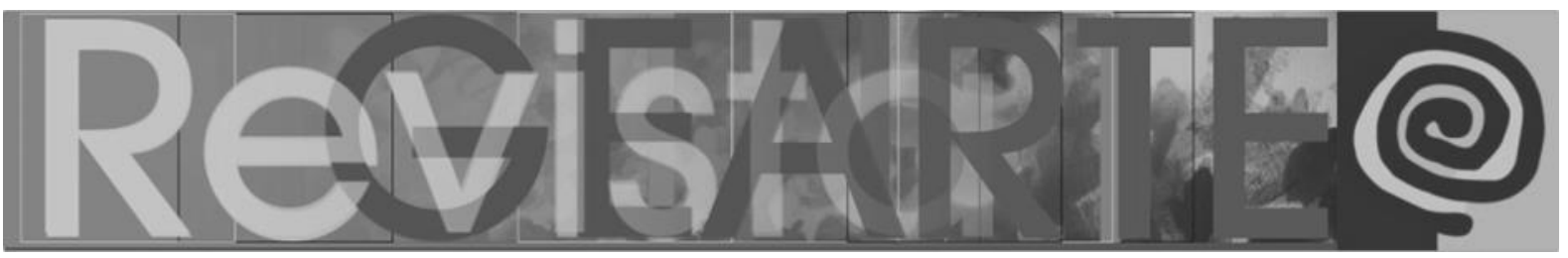

Cada clase giró en torno a un tema concreto: la diversidad de la identidad sexual, la sociedad de la vigilancia, el multiculturalismo, el problema del mal, el/la maestro/a ideal, los ideales de belleza, el amor romántico, la diversidad funcional, la presión social de los grupos, la felicidad... Cada asunto suscitaba visionar un capítulo de una serie que elegía el subgrupo que decidía el tema transversal del día y que se analizaba desde la cultura visual. Hacia la mitad de la clase se desarrollaba una merienda temática (figuras 2 y 3 ) y se bailaba con una playlist de canciones también acorde al asunto. Algunas intervenciones produjeron performances (Figura 4), otras instalaciones, propuestas de taller plástico en el aula y desde luego infinidad de debates en gran grupo y en pequeño grupo.

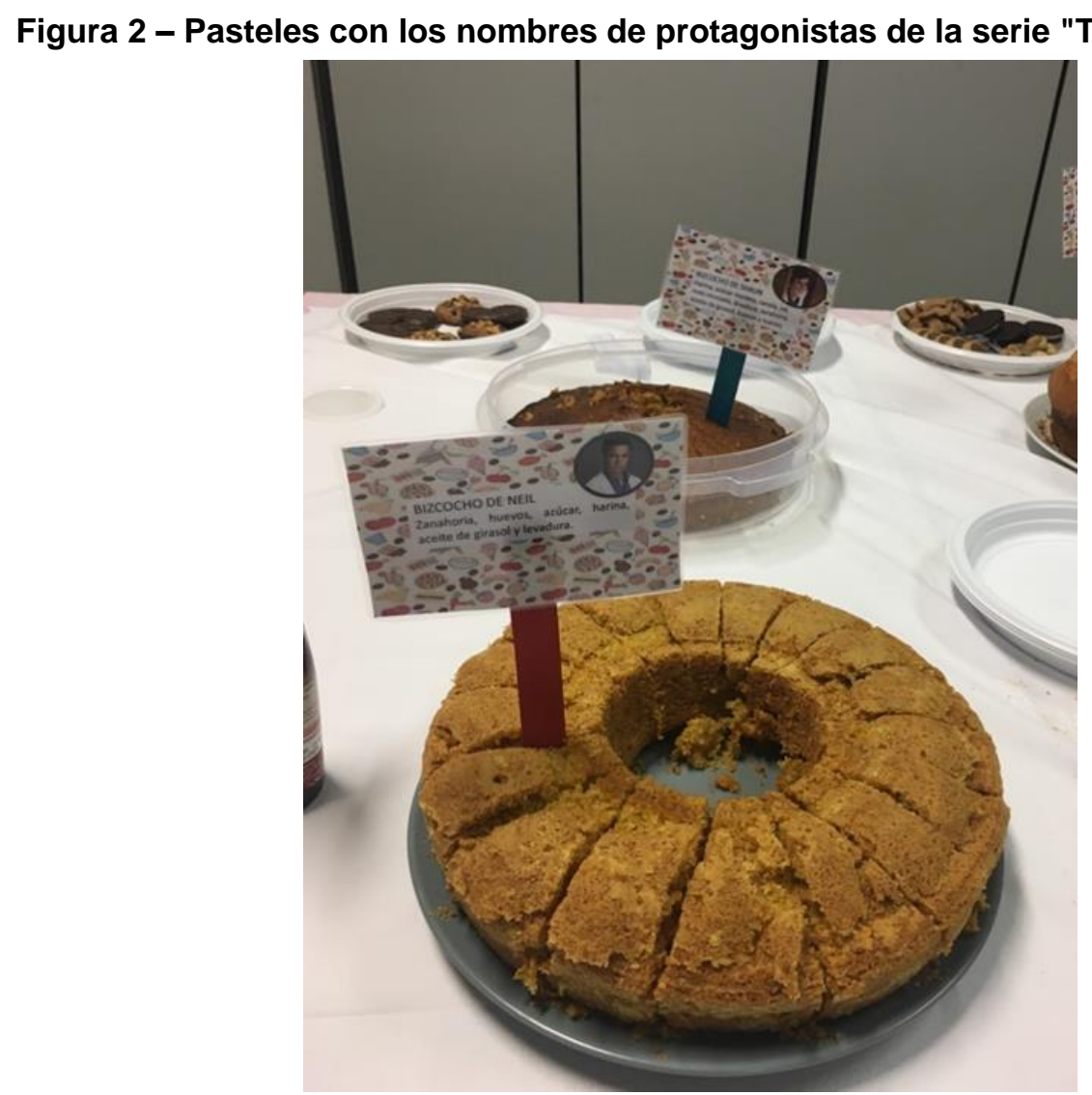

Fuente: Archivo de las autoras. 


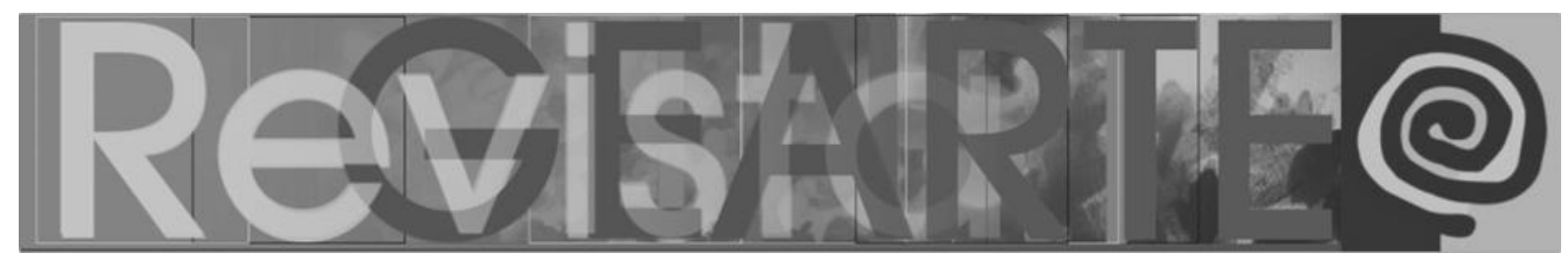

Figura 3 - Merienda del día del multiculturalismo, la mesa de Portugal

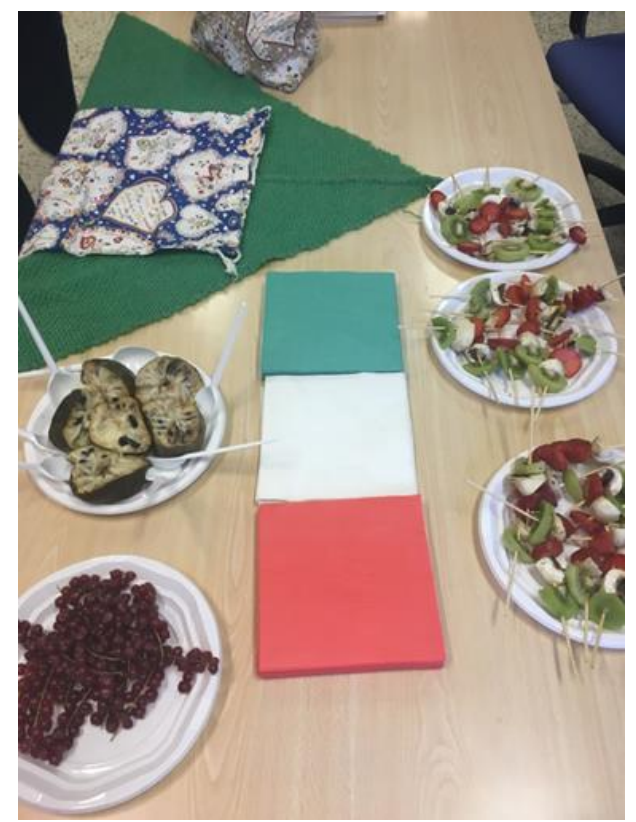

Fuente: Archivo de las autoras

Figura 4 - Durante una dinámica interactiva

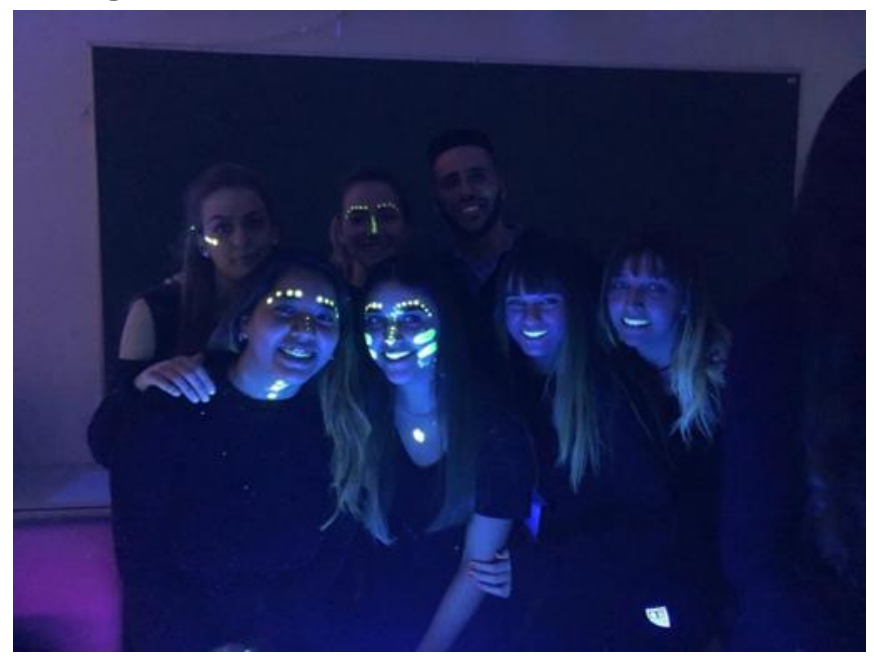

Fuente: Archivo de las autoras

Se generaron dos vídeos ${ }^{7}$ a partir de sendas performances colectivas, uno de ellos a propósito de un proceso de elaboración de un personaje performático colectivo (figuras 5 y 6), y el segundo haciendo realidad una fantasía diurna de la co-docente Pilar Pérez durante su viaje a un Congreso de Educación Artística en

7 De la performance "Ceci n'est pas une classe": https://www.youtube.com/watch?v=z_QEh9AEa6Q\&t=1s; De la performance "Good Night Namibia": https://www.youtube.com/watch?v=L4S6r8tsVSc\&t=2s 


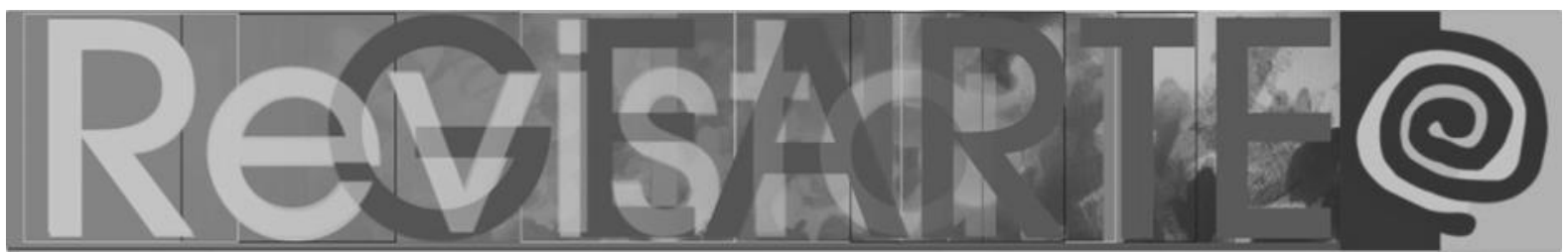

Namibia, compartido con los estudiantes a posteriori para suscitar un feedback de imágenes y llevado a cabo usando un croma (Figura 7). También se trabajó el cuento de hadas de Barba Azul realizando una deriva arquetípica a la ciudad de Toledo (Figura 8).

Figura 5 - Durante la performance de construcción de un personaje colectivo

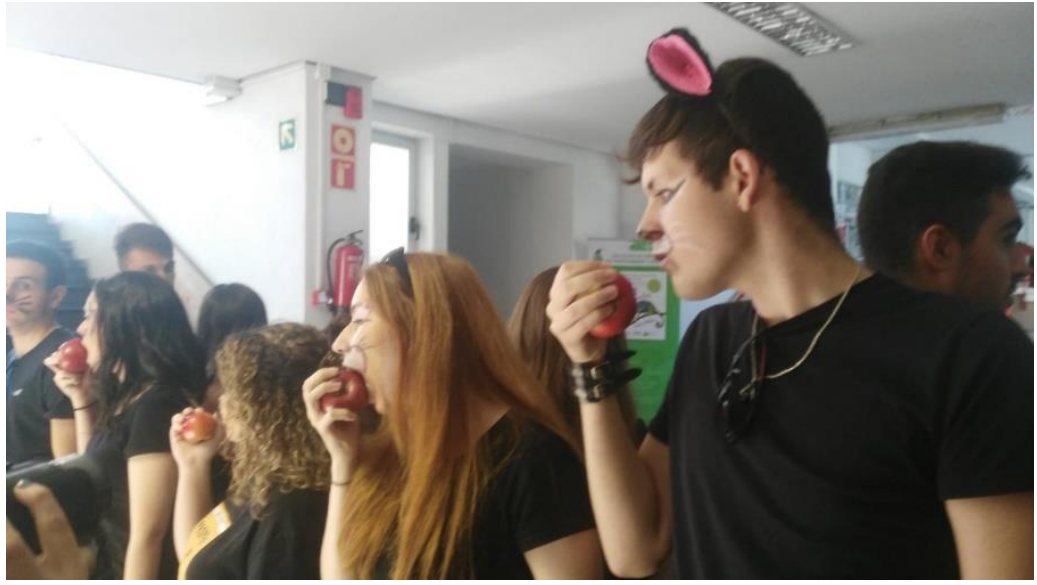

Fuente: Archivo de las autoras.

Figura 6 - Durante la performance en que se construyó un personaje colectivo

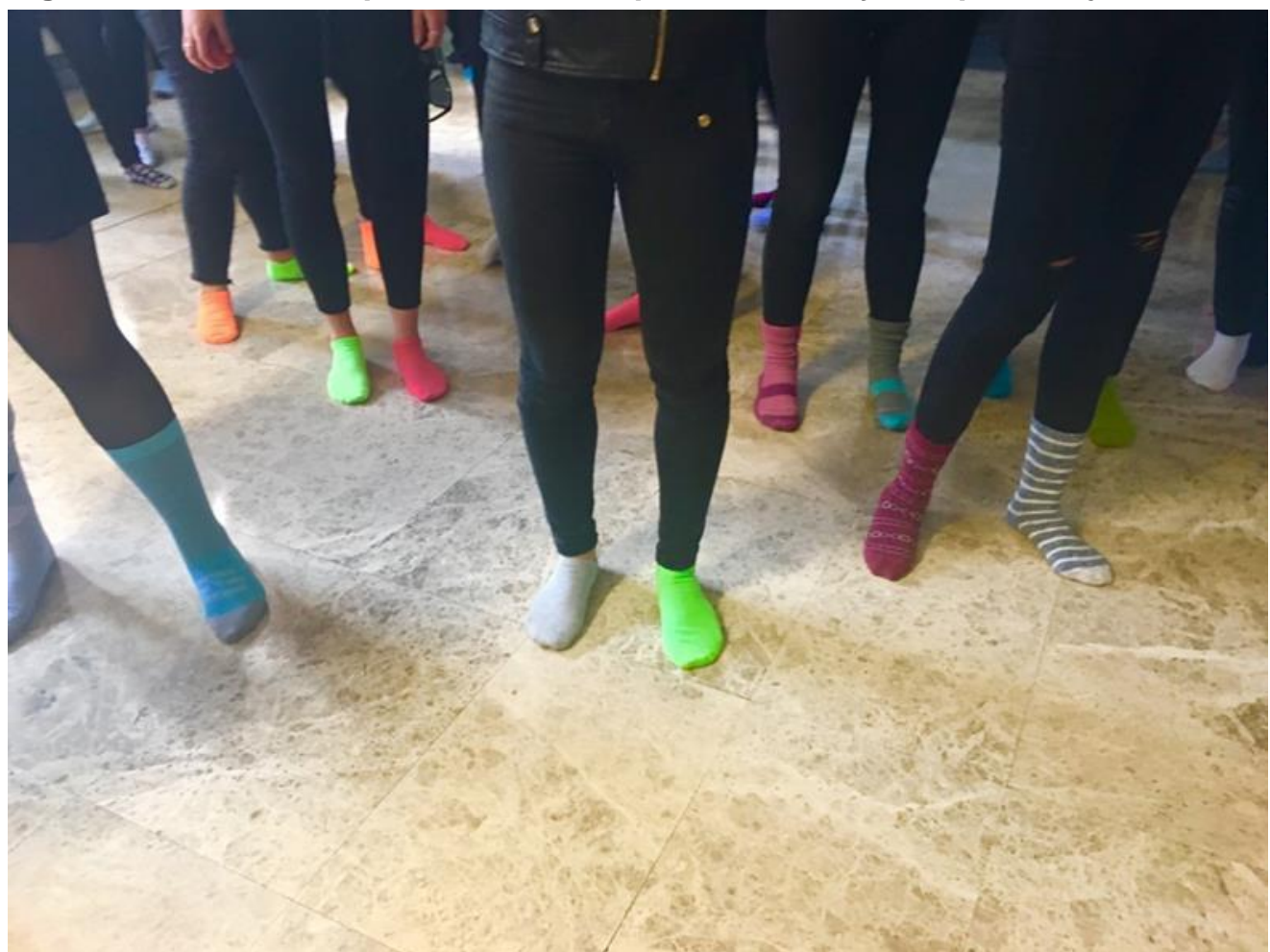

Fuente: Archivo de las autoras.

PÉREZ CAMARERO, Pilar; ALEGRE DEL REY, María Ángeles. Propuesta de colaboración con futuros docentes de educación infantil. Bocadillos temáticos, series, performances e instalaciones. Revista GEARTE, Porto Alegre, v. 7, n. 2, p. 401-419, maio/ago. 2020.

Disponível em: http://seer.ufrgs.br/gearte 


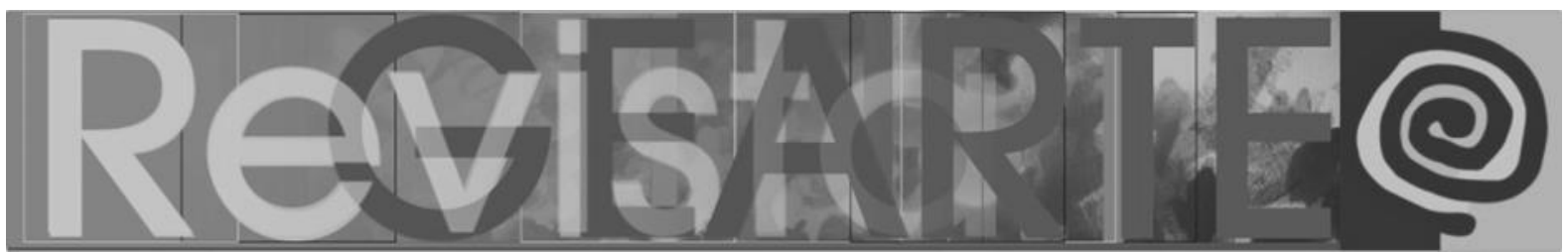

Figura 7 - Durante la grabación de la performance sobre Namibia

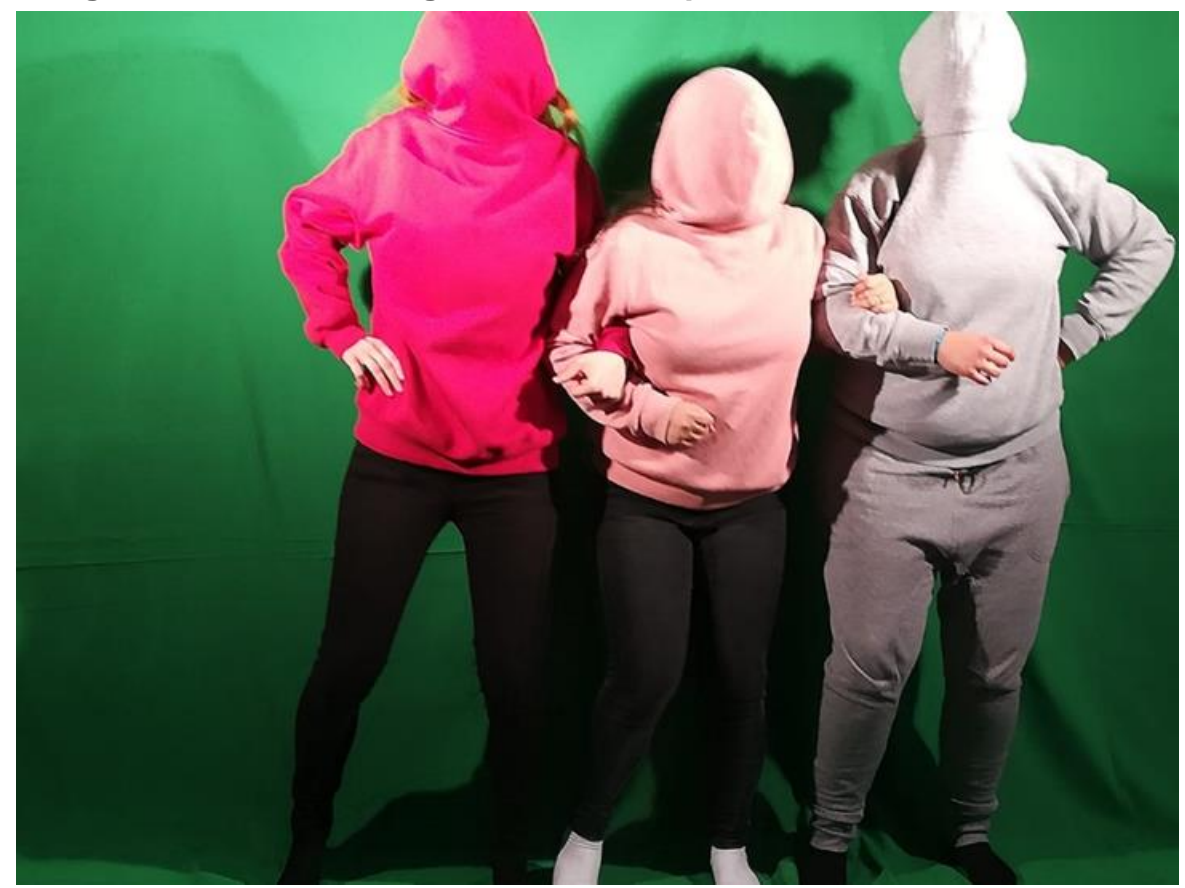

Fuente: Archivo de las autoras.

Figura 8 - Dramatización del cuento en la deriva a Toledo

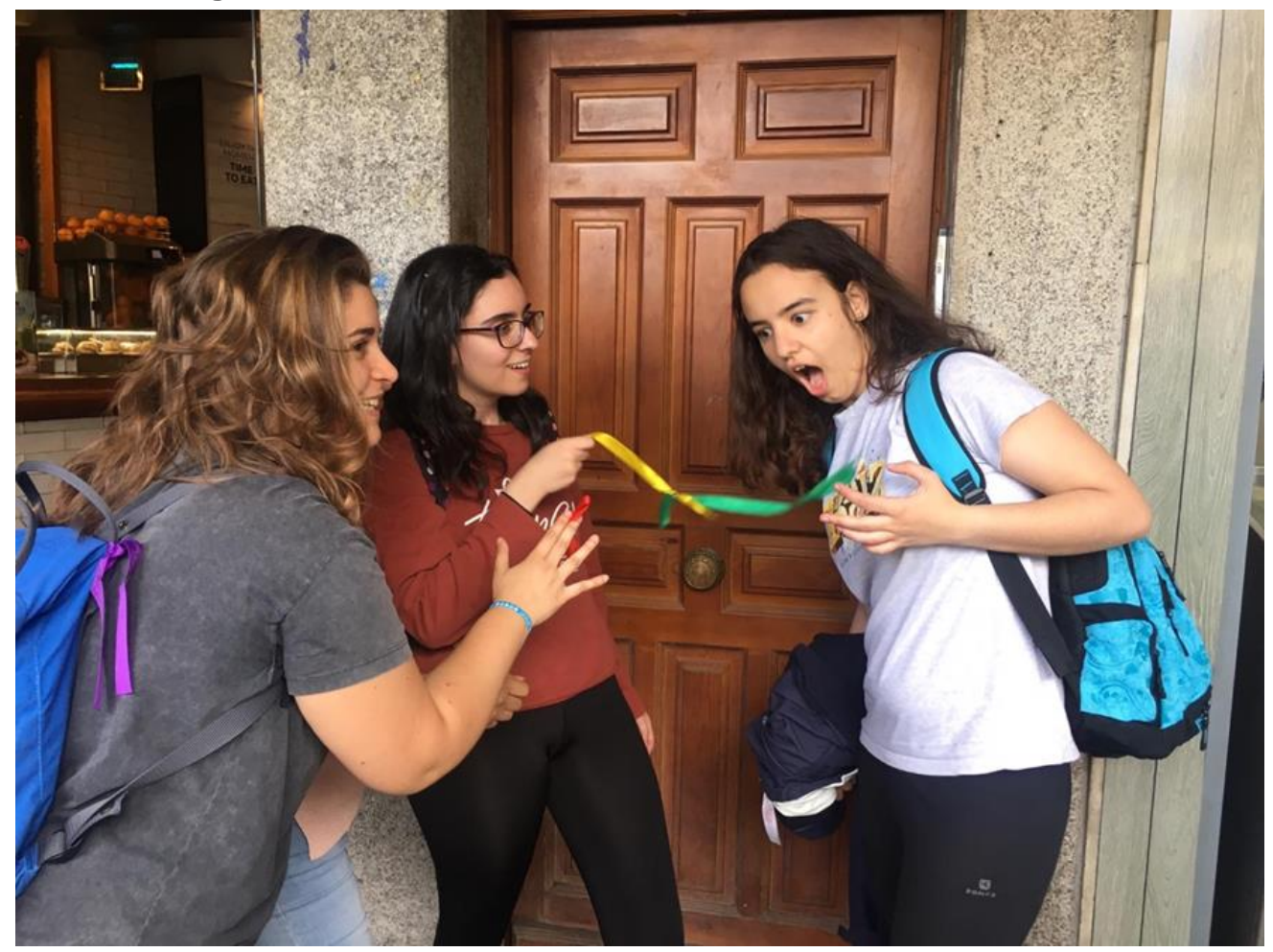

Fuente: Archivo de las autoras.

PÉREZ CAMARERO, Pilar; ALEGRE DEL REY, María Ángeles. Propuesta de colaboración con futuros docentes de educación infantil. Bocadillos temáticos, series, performances e instalaciones. Revista GEARTE, Porto Alegre, v. 7, n. 2, p. 401-419, maio/ago. 2020.

Disponível em: http://seer.ufrgs.br/gearte 


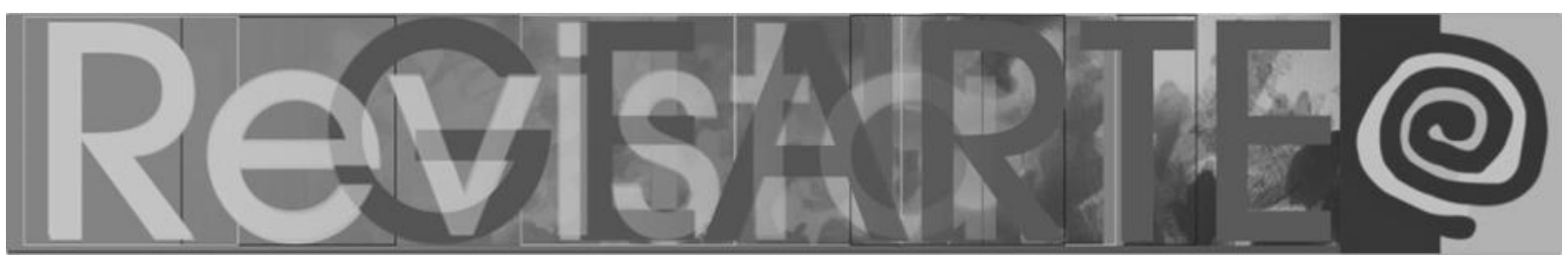

Señalar que a lo largo de los años hemos incorporado la transferencia Universidad/Entorno, favoreciendo que participaran en las clases familiares, amigos con lo que hemos tenido personas de todas las edades, de niños a adultos acompañando los encuentros. Significar la clase abierta en torno a cuentos Disney celebrada en el año 2017: "Los cuentos como recurso didáctico para la comprensión de la cultura visual". Como experta nos visitó Judith García Cuesta dentro del ciclo de actividades culturales de la Facultad de Formación de Profesorado, Universidad Autónoma de Madrid (UAM), y se nos unieron grupos familiares de todas las edades.

También hemos propiciado la ocasión para recibir los animales de las familias en la clase, acercando la realidad del aula de infantil en que a veces se cuidan mascotas y observando el gran poder educativo que las criaturas de compañía tienen para los seres humanos. Estos factores beneficiaron el clima del aula y ayudaron a acercar la realidad de la vida externa a la universidad acercando los espacios y eliminando fronteras.

A su vez resulta relevante el evento con sesgo de género desarrollado para el 8 de marzo de 2019 y en el marco de las actividades culturales de la Facultad de Formación del Profesorado con el diseño de la "Jornada de la Falda", en la Facultad de Formación de Profesorado dentro de un evento para celebrar el 8 de marzo, organizado por M"José Álvarez, Vicedecana de Cultura. Ese día analizamos y reflexionamos juntos acerca de la falda como icono femenino utilizado con dificultad por los hombres y asistimos a clase portando una falda, todos, hombres y mujeres (Figura 9). 


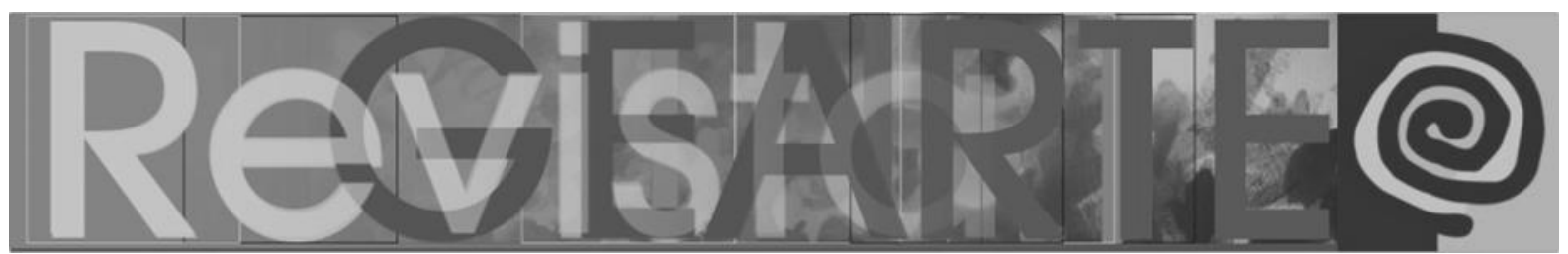

Figura $9-$ Todos y todas con falda

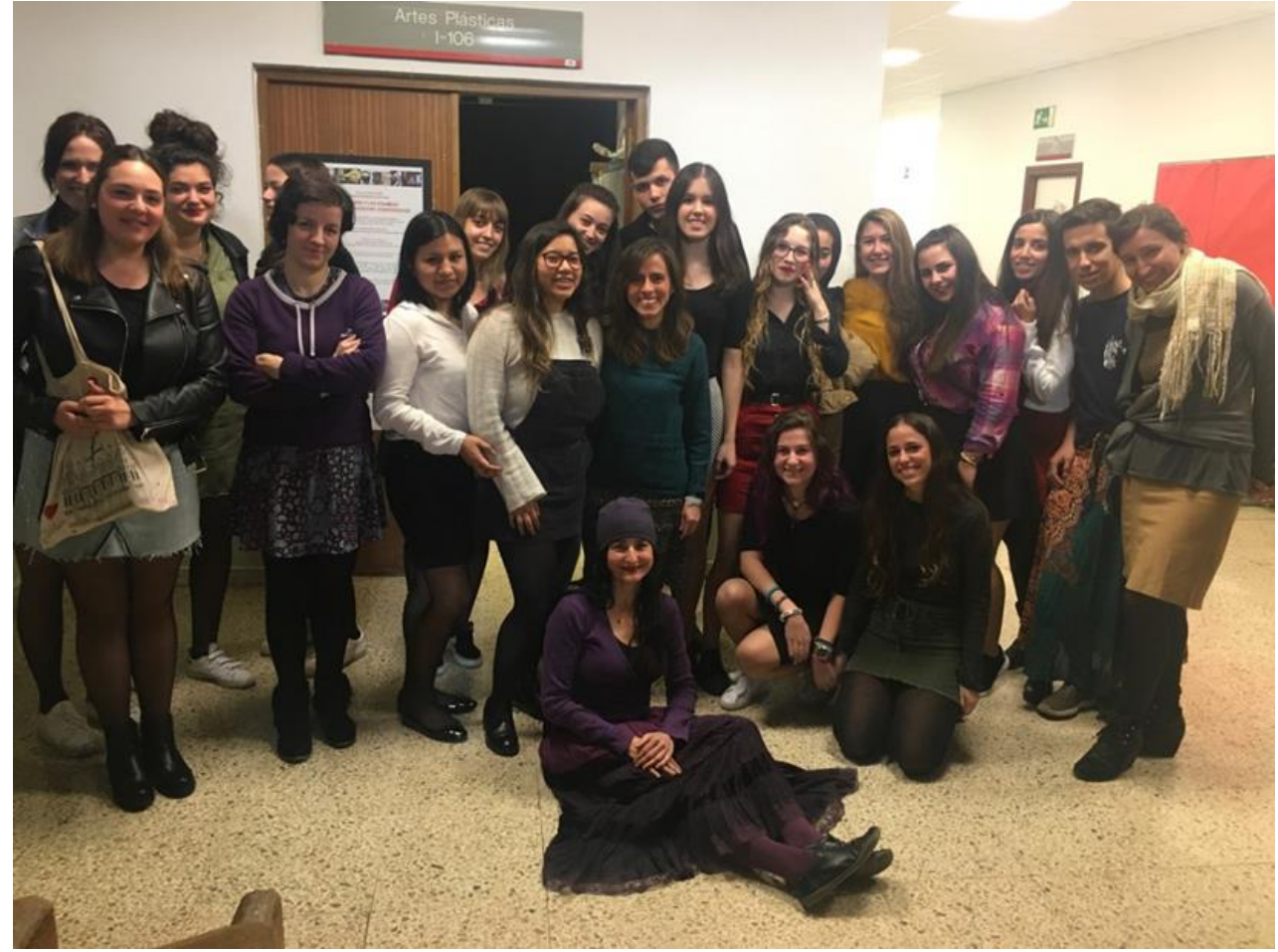

Fuente: Archivo de las autoras.

Volviendo al asunto clave de la autogestión responsable, damos cuenta de la importancia de concebir las sinergias que se activan conjugando teoría práctica y capacidad de auto organización del alumnado, pues se puede garantizar el éxito en el desarrollo de competencias generales y específicas de la titulación y materia en sus tres dimensiones (conocimientos, habilidades y actitudes), pues las mismas solo tienen lugar con verdadera consistencia cuando confluyen desde los tres aspectos principales del acontecer humano "la vivencia, la expresión y la comprensión" Dilthey.

Es desde aquí desde donde apuntamos las principales líneas de acción que se desplegaron y desarrollaron a través de este proyecto de innovación que pusimos en práctica:

- Incorporación de metodologías activas que facilitan el desarrollo de competencias tanto generales como específicas y transversales, que incrementan el grado de motivación de los estudiantes por el aprendizaje. 


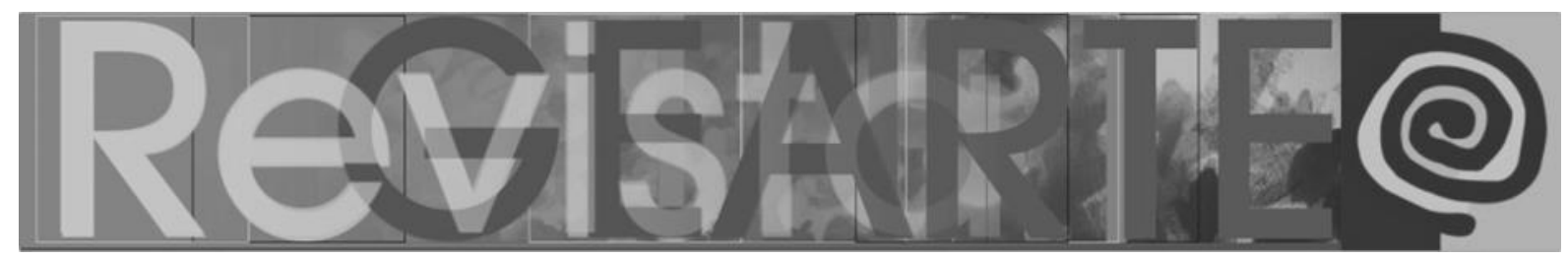

- Proyectos de Innovación que impulsan la inclusión educativa en la docencia Universitaria.

- Identificación de buenas prácticas en la docencia universitaria que incluyen la perspectiva de género.

La formación del maestro en educación artística supone el diseño y activación de una pedagogía configurada en la puesta en práctica de procesos artísticos creativos que fomenten y aborden la profundización tanto de la inclusión como de la cuestión de género desde el diálogo y conocimiento a su vez entre distintas perspectivas. Ambos aspectos que se incluyen en el desarrollo de competencias (conceptuales, procedimentales y actitudinales) de la materia han de pasar por el objetivo principal de aprender a articular un desarrollo de la conciencia que concibe la lectura, apertura y reflexión crítica del momento presente. Es así que en aras de una necesaria profundización que la innovación en los aspectos metodológicos que proponemos no se limita a incentivar la expresión de lo aprendido si no a su vez parafraseando a Certeau (2002) a "entrar en el baile". A entrar en la vivencia, dotando a la acción educativa de un enfoque performático donde lo interpretativo y simbólico constituye el punto de ignición del proyecto de innovación que realizamos. Supone este un modo de evitar que la innovación se convierta en una mera sucesión de cambios motivados únicamente por las corrientes y circunstancias coyunturales de momento. $\mathrm{Y}$ muy al contrario constituye un único modo de promover una innovación que por su profundidad trascienda el instante presente y revierta en la edificación existencial de todos los agentes educativos implicados. La multiplicidad de factores que intervienen de manera simultánea en el hecho educativo como bien subrayó Jackson (1992) en su renombrado libro La vida en las aulas, requiere de la activación de este objetivo. Su consecución, su logro, apunta a las competencias esenciales que ha de adquirir todo profesional de la educación. Competencias que en su integridad, coherencia y puesta en práctica aglutinan de manera simultánea triple naturaleza: conceptual, procedimental, actitudinal. 


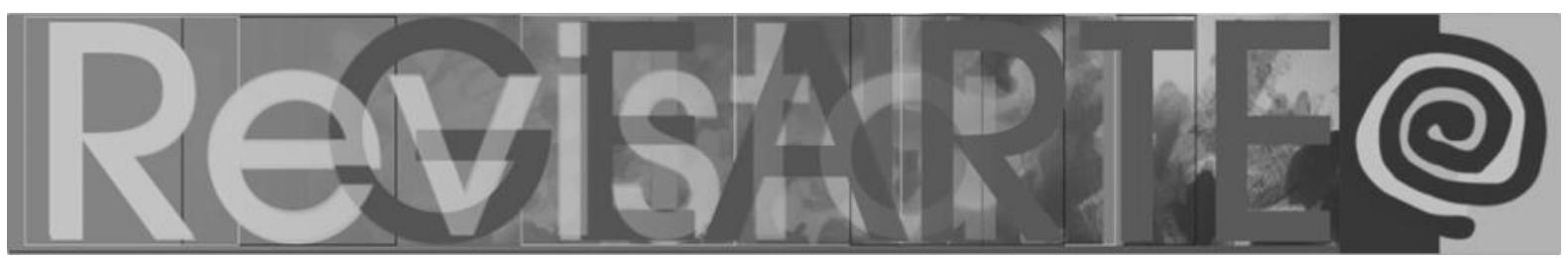

Podemos con ello constituir y nombrar el objetivo general del proyecto: desplegar la dinámica pedagógica generativa de la innovación en las clases de educación artística.

Y así mismo constituimos y nombramos los objetivos específicos:

- Poner en práctica las estrategias que sistematicen el planteamiento señalado.

- Posibilitar la implementación de la actividad docente a la apertura de la realidad y desarrollo conciencial y artístico de cada grupo.

A continuación detallamos los aspectos esenciales a través de los que se articularon los objetivos específicos. Como se puede apreciar dirigidos a la aplicación de los paradigmas de la Educación Artística bajo los parámetros de la innovación docente que estamos analizando.

1. Poner en práctica las estrategias que sistematicen el planteamiento señalado: (sistematizar estrategias que posibiliten la observación participante de los estudiantes sobre su propio aprendizaje).

2. Potenciar la lectura analítica visual del contexto donde se desarrollan.

3. Potenciar la reflexión sobre los propios diseños de acción que los alumnos elaboran y desarrollan en la clase.

4. Desarrollar estrategias de crítica constructiva en los estudiantes sobre su propia planificación, proceso y desarrollo de actividades.

5. Favorecer la creatividad individual y colectiva en los diversos procesos de creación.

En definitiva se trata de un proceso que ha ido madurando a lo largo de los años produciendo diferentes sinergias, construyendo un aprendizaje vivo entre todos (mejora del aprendizaje de los estudiantes; mejora de la enseñanza de los docentes) y cuya fundamentación se sustenta en el enfoque señalado anteriormente.

Pusimos en práctica las estrategias que sistematizaron un planteamiento innovador, que pretendió a su vez su apertura a la realidad de cada grupo. El último

PÉREZ CAMARERO, Pilar; ALEGRE DEL REY, María Ángeles. Propuesta de colaboración con 413 futuros docentes de educación infantil. Bocadillos temáticos, series, performances e instalaciones. Revista GEARTE, Porto Alegre, v. 7, n. 2, p. 401-419, maio/ago. 2020.

Disponível em: http://seer.ufrgs.br/gearte 


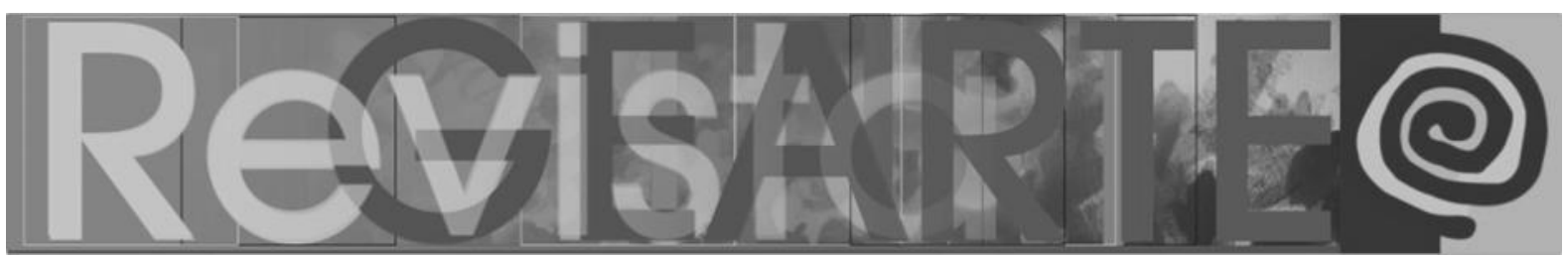

curso se trató de consolidar su estructura (que recogía el recorrido llevado a cabo hasta el momento) y con esta base fundamentada se constituía un bagaje teóricopráctico desarrollado desplegando la dinámica pedagógica generativa de la innovación y de la que se infiere un análisis teórico.

Esto pasa por una lectura simbólica de las puestas en acción tanto de las actividades desarrolladas como de las manifestaciones expresadas en el transcurso de las mismas bajo la recopilación y reflexión de indicadores en base a las competencias que se pretendían desarrollar a través de la materia impartida.

Los indicadores de seguimiento y evaluación vienen precedidos por la observación participante y la elaboración de diarios de campo. Los diarios de campo constituyen herramientas/estrategias para la recopilación de indicadores de seguimiento y evaluación de aplicación del proyecto dirigidos a la vivencia, expresión y comprensión de los estudiantes y docentes; de los estudiantes en cuanto a su aprendizaje en relación al objetivo principal de la materia y de los docentes en relación a la mejora de la enseñanza en base al proyecto de innovación desarrollado (Quadro 1).

Quadro 1 - Modelo de registro en el diario de campo del equipo investigador

\begin{tabular}{|l|l|l|}
\hline Nota de campo & $\begin{array}{l}\text { Relato de } \\
\text { campo }\end{array}$ & Clave de campo \\
\hline $\begin{array}{l}\text { Breve apunte a modo } \\
\text { de titular de lo } \\
\text { acontecido }\end{array}$ & $\begin{array}{l}\text { Relato } \\
\text { narración }\end{array}$ & $\begin{array}{l}\text { Palabras llave, tema y temas que sugiere el hecho } \\
\text { narrado. Enlaces temáticos y triangulación con } \\
\text { otras reflexiones. }\end{array}$ \\
\hline
\end{tabular}

Fuente: Tesis de María Ángeles Alegre del Rey (2017)

Utilizamos registro fotográfico y audiovisual tanto los estudiantes como los miembros del equipo de investigación.

Un aspecto en el que recabamos especialmente, de resultas de otros años, y en el que seguimos profundizando fue tratar de que el valor que imperase en la propuesta fuera solidario y cooperativo, donde la competencia se estimule a que 


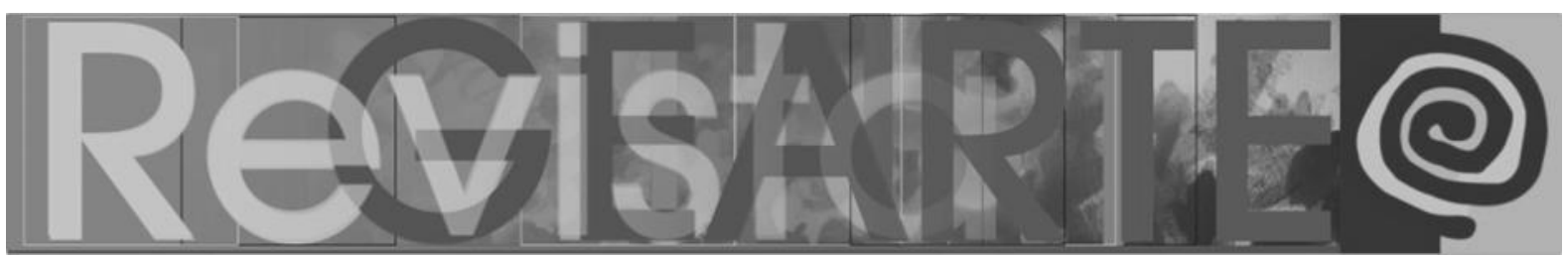

sea consigo mismos más que con el resto del grupo, potenciando la autocrítica y el cuestionamiento ante posiciones más egoícas y donde la calificación en concurrencia con otros es lo prioritario.

También nos interesaba trabajar los conceptos de aprecio por la diversidad y el tratar en equidad lo diferente. Es importante ubicar todo esto en el hecho de que estamos formando a futuros maestros y lo que sea más relevante en la forma de construir su formación, para nosotros, tiene toda su fundamentación en el desvelar y profundizar los valores de lo humano, el respeto, la integridad y la coherencia, por encima de la competitividad. Indudablemente observamos el grado de satisfacción de los implicados en el proceso, principalmente los estudiantes, pero también del resto de productores de conocimiento, pues todo este proyecto se concibe como comunitario, gestionado por todos y vivo en tanto se crea por los implicados en el mismo.

Desde que se inició el semestre, trabajamos utilizando cuadernos de bitácoras/cuadernos de campo señalados y registro fotográfico y de vídeo, donde se documentó todo lo que pasó y como material idóneo para analizar los sucesivos procesos.

Nos íbamos reuniendo periódicamente llevando a cabo una evaluación continua y procesual y siendo Pilar Pérez Camarero responsable de la asignatura, contó con la co-docente María Ángeles Alegre de forma periódica para desarrollar las diversas acciones. Se procuró que los estudiantes estuvieron al tanto desde el primer momento de lo que del registro se iba desarrollando y procuramos contar con el ajuste de sus expresiones y reflexiones tanto en lo que a contenidos y su desarrollo se trata como en lo referido a sus propuestas de acción y concepción vinculadas al desarrollo de las actividades y sentir acerca de la propuesta.

Con la metodología aplicada fuimos responsables de que los estudiantes acabaran el curso comprendiendo la materia y contando con una base teórico/práctica acorde a la misma. Evaluamos de manera continua y procesual la 


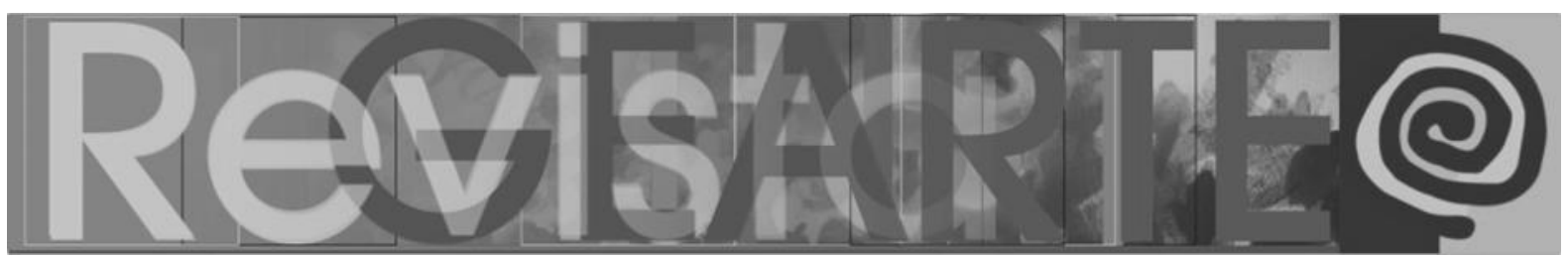

actividad docente desarrollada de cara a ajustar las actividades y tareas a los procesos de aprendizaje del grupo y de cada alumno en sinergia con el resto y con las propias actividades desarrolladas. A su vez fue la responsabilidad de la titular de la asignatura la coordinación de todo el conjunto de acciones y de propuestas, así como de sugerir y acompañar en la dirección que la materia presupone.

Tratándose de un grupo grande, de casi setenta estudiantes, contamos con su distribución en subgrupos gestionados por los propios estudiantes. De esta manera la clase se armó desde el grupo total, a los subgrupos y a interacciones entre ellos, con la fluidez que permitió la autogestión del horario y de las responsabilidades. Trabajando también con representantes de los subgrupos para agilizar tareas de coordinación como hemos hecho otros años. El sistema de trabajo permitió que los liderazgos se intercambiaran y que todos los agentes del proceso educativo tuvieran peso y tomaran decisiones de enseñanza/aprendizaje.

Así tratándose de una metodología de trabajo que se inserta en la investigación/ acción busca elementos de radicalidad y trascendencia. Radicalidad entendida como la articulación de estrategias dirigidas de manera ineludible a procesos de desarrollo de conciencia de los futuros docentes. La innovación que propusimos entendemos fomentó en el futuro profesorado la innovación que supone aprender a pensar y organizar la acción y expresión artística abierta al trascurso de las posibilidades latentes que encierra el presente y que se manifiestan en los múltiples detalles que se observan en el transcurrir de las aulas. Nuestro proceso se alimentó de los recursos que vienen de la creatividad y la pedagogía, de la interacción con las escuelas y de la filosofía pedagógica. Contemplamos una educación artística que se movió en el espacio interdisciplinar de la cultura visual y la visión holística de lo humano, favoreciendo sobre todo la educación en valores y en lo que al arte se refiere, dando un espacio fundamental al arte contemporáneo pues es el que se está produciendo en la sociedad en que vivimos y nosotras nos consolidamos como artistas educadoras, con esta visión y planteamiento dual, en una coherencia de identidad defendida en los foros 


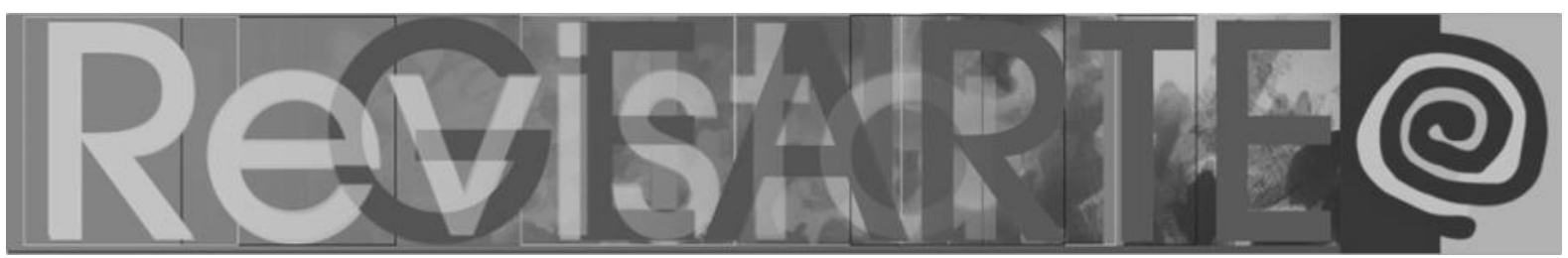

internacionales de nuestra área, concretamente privilegiamos las visiones que se desprenden desde InSEA ${ }^{8}$ Internacional de la que somos miembros, la asociación puntera en Educación Artística que aboga por la implementación de un hacer educativo y desde la doble identidad del artista/profesor. Semejante es la tendencia que hemos vivido en otros espacios análogos como es la labor desarrollada por la Fundación Yehudi Menuhin Internacional, y Yehudi Menuhin España, en que se introduce el arte en las escuelas, precisamente por artistas que desarrollan también un trabajo docente y con quien también hemos colaborado en su día.

Abogamos además, por una visión interdisciplinar de las artes, como corresponde al trabajo con el arte en la escuela y más concretamente en la etapa de educación Infantil.

En resumen, podemos decir, que con todo esto, se garantizó el impulso y desarrollo de una nueva configuración en la articulación de la acción docente con los consiguientes resultados de aprendizaje, (activación de laboratorio interior) y calidad educativa. Se optimizaron los procesos tanto de registro, como de contraste, discusión y satisfacción de los implicados (estudiantes y docentes/equipo investigador).

Este tipo de iniciativas promueven la posibilidad de imaginar una universidad diferente, dentro del rigor que lo académico precisa. Se apoyan en la capacidad creadora, autogestora y responsable de los estudiantes y su capacidad para decidir y autoproducir situaciones de aprendizaje y construcción de espacios educativos.

A partir de aquí se podrían desarrollar otras intervenciones y afianzando la parte de registro y adquisición de conciencia y capacidad crítica construir una batería conceptual basada en la práctica, que apoye posibilidades de enseñanza novedosas y que pueden producir recelo o cierta incomprensión si no se ha vivido la experiencia previa. Es por ello que trabajamos desde la experiencia y

8 International Society of Education through Art (InSEA). 


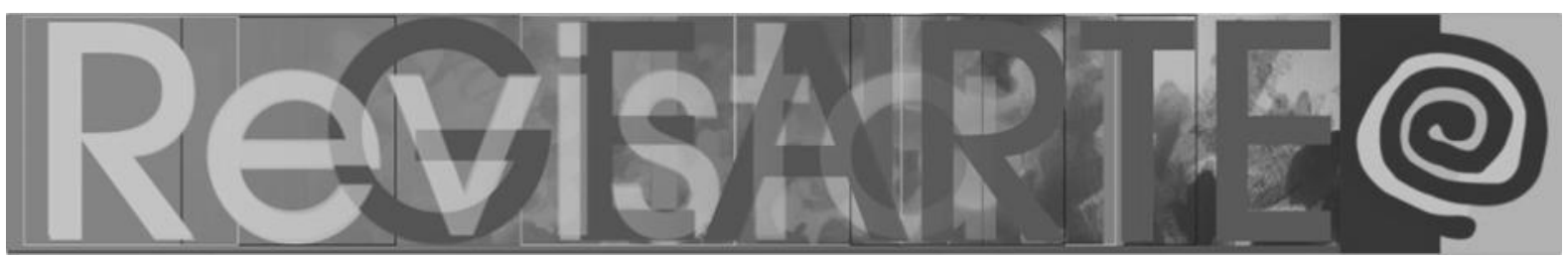

pretendemos justamente seguir investigando a partir de un riesgo que ya conocemos por haberlo estado viviendo en los años precedentes en que hemos aprendido y mejorado con la práctica, y las colaboraciones puntuales externas.

Los cuadernos diarios de clase, la comparativa con los años de implementación de este tipo de innovación docente que flexibiliza, pone el foco y la responsabilidad en el estudiante, nos serán también muy útiles para ver qué hemos mejorado y en qué podemos seguir avanzando, algo que requiere su tiempo de incubación, de análisis contrastado con otras posibilidades, algo en lo que actualmente estamos trabajando.

\section{Referencias}

ALEGRE DEL REY, María Ángeles. Análisis simbólico de los trastornos de espectro autista y de los trastornos de déficit de atención con hiperactividad en el ejercicio de la orientación escolar. Fundamentos para la evolución de las instituciones escolares. UAM, 2017. Tesis Doctorales en Educación - Facultad de Formación de Profesorado y Educación, Universidad Autónoma de Madrid, Madrid, 2017. Disponível en: http://repositorio.uam.es/handle/10486/680445

CERTEAU, Michel de. La invención de lo cotidiano. 1 Artes de Hacer. México, D. F: Instituto Tecnológico y de estudios Superiores de Occidente, 2002.

DE LA HERRÁN, Agustín. El nuevo "paradigma" complejo-evolucionista en educación. En: DE LA HERRÁN, A.; HASHIMOTO, E. y MACHADO, E. Investigar en Educación: Fundamentos, aplicación y nuevas perspectivas. Madrid: Dilex (capítulo 13), 2005.

DE LA HERRÁN, Agustín; PAREDES, Joaquín (Coords.). Promover el cambio pedagógico en la Universidad. Madrid: Ediciones Pirámide (Grupo Anaya, S.A.), 2012.

GADAMER, Hans-Georg. Estética y Hermenéutica. Madrid: Tecnos. Grupo Anaya, S.A, 2011.

JACKSON, Philip. La vida en las aulas. Madrid: Morata, S.A, 1992.

LAGE DE LA ROSA, Marta; PÉREZ CAMARERO, Pilar. Muñecas como yo: volver a pensar las muñecas. Padres y maestros. Revista de Investigación e Información Pedagógica, n. 375, p. 28-31, sept. 2018. Disponible en: https://fund-encuentro.org/index.php/padresymaestros/issue/view/654. Acceso en: 12 diciembre 2019.

PÉREZ CAMARERO, Pilar. Transformando una muñeca: arquetipos y proyección simbólica a través de un taller de arte". Actas de El cuerpo como medida, Universidad Rey Juan Carlos. Editora Mãuesús Abad Tejerina. ISBN- 978-84-608-1694-2 (pp 138-149p), 2016. Disponible en: https://eciencia.urjc.es/bitstream/handle/10115/14461/elcuerpocomomedida2.pdf?sequence=1\&is Allowed=y. Acceso en: 10 diciembre 2019.

PÉREZ, Pilar. (Org.). De muñeca estereotipada a gente 'normal'. Madrid: Universidad Autónoma de Madrid, 2016. Disponible en:

https://www.academia.edu/30516684/De_mu\%C3\%B1eca_estereotipada_a_gente_normal. Acceso en: 9 diciembre 2019. 


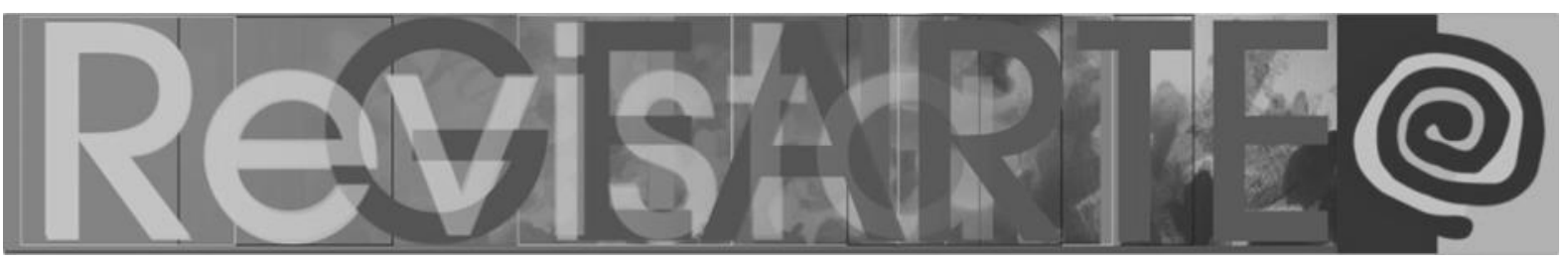

\section{Pilar Pérez}

Doctora en Bellas Artes por la Universidad Complutense de Madrid (UCM) y Experta en Educación Artística por la UCM. Posgraduada en Psicoanálisis Analítico por la Universidad Ramón Llull de Barcelona. Profesora Titular en el Departamento de Educación Artística, Plástica y Visual. Mi experiencia como docente comienza en el tiempo de mi formación doctoral en el Departamento de Bellas Artes de la UCM, y en diversas estancias en universidades de Latinoamérica (Cuba, México y Brasil). Después he desarrollado mi trabajo en la Universidad Autónoma de Madrid (UAM) en formación de profesores desde 1999, en el Doctorado de Creatividad Aplicada y en el de Arte terapia en contextos sociales diversos, ahora Máster de Arte Terapia y Título Propio de Creatividad Aplicada.

ORCID: http://orcid.org/0000-0002-0210-6111

E-mail: p.perez@uam.es / bandeirapilar@gmail.com

Currículo: http://www.gice-uam.es/amo-team/pilar-perez-camarero/

\section{María Ángeles Alegre del Rey}

Doctora en Educación por la Universidad Autónoma de Madrid. Departamento de Didáctica y Teoría de la Educación y Departamento de Educación Artística, Plástica y Visual. Licenciada en Filosofía y Ciencias de la Educación por la Universidad Complutense de Madrid. Perteneciente al cuerpo de profesores de Enseñanza Secundaria - Especialidad Psicología - Pedagogía. Profesora Honoraria en el Departamento de Educación Artística, Plástica y Visual de la Facultad de Formación de Profesorado y Educación. UAM

ORCID: http://orcid.org/0000-0002-7961-7948

E-mail: malegredelrey@educa.madrid.org / marianalegre4@hotmail.com

Recebido em 29 de fevereiro de 2020 Aceito em 19 de maio de 2020 